\title{
Cement Minerals At Elevated Tempera'ure: Thermodynamic and Structural Characteristics
}

\author{
C.J. Bruton \\ B.L. Phillips \\ A. Meike \\ S. Martin \\ B.E. Viani
}

This paper was prepared for submittal to the

Materials Research Society

Boston, MA

November 29 - December 3, 1993

November 1993

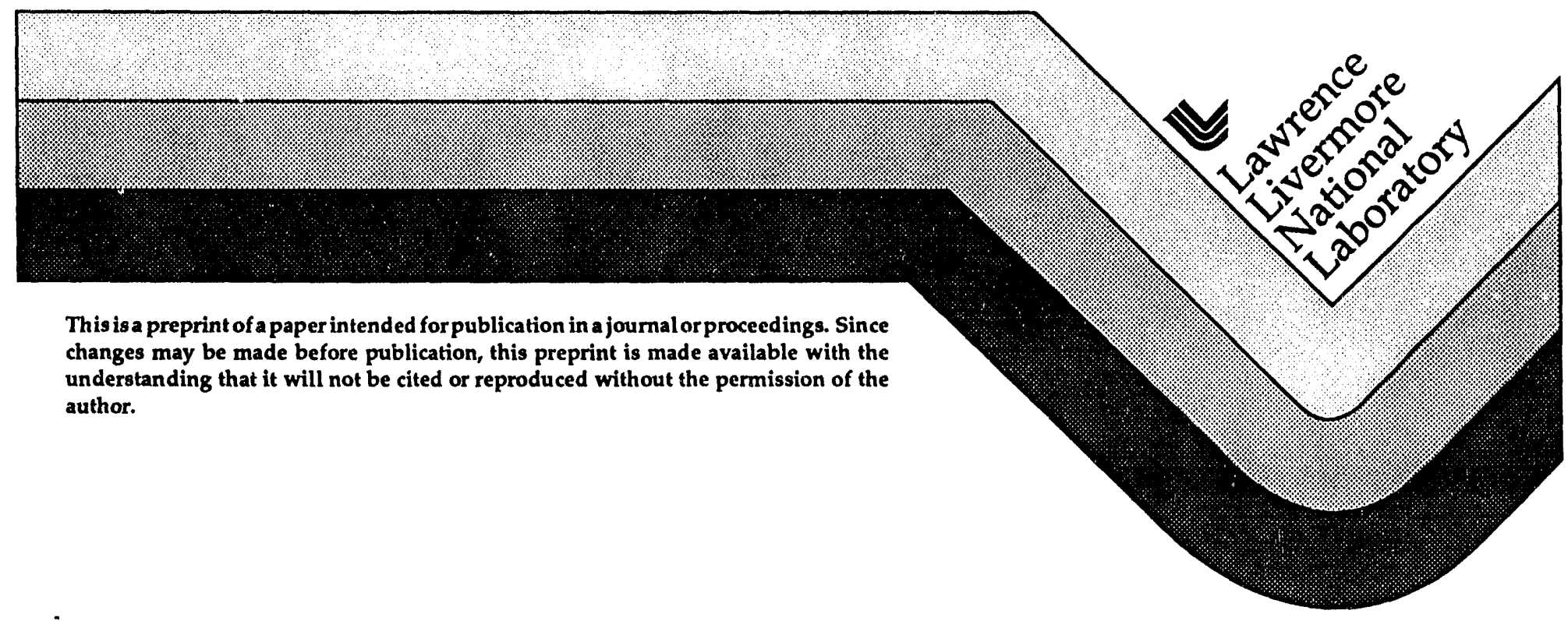


DISCLAIMER

This document was prepared as an account of work sponsored by an agency of the United States Government. Neither the United States Government nor the University of California nor any of their employees, makes any warranty, express or implied, or assumes any legal liability or responsibility for the accu racy, completeness, or usefulness of any information, apparatus, product, or process disclosed, or represents that its use would not infringe privately owned rights. Reference herein to any specific commercial products, process, or service by trade name, trademark, manufacturer, or otherwise, does not necessarily constitute or imply its endorsement, recommendation, or favoring by the United States Government or the University of California. The views and opinions of authors expressed herein do not necessarily state or reflect those of the United States Government or the University of Califormia, and shall not be used for advertising or product endorsement purposes. 


\title{
CEMENT MINERALS AT ELEVATED TEMPERATURE: THERMODYNAMIC AND STRUCTURAL CHARACTERISTICS
}

\author{
CAROL J. BRUTON, BRIAN L. PHILLIPS, ANNEMARIE MEIKE, SUE MARTIN AND \\ BRIAN E. VIANI \\ Lawrence Livermore National Laboratory, L-219, P.O. Box 808, Livermore, CA 94550
}

\begin{abstract}
An experimental and modeling program has been designed to elucidate the structural and thermodynamic response of cement minerals to elevated temperature. The components of the program include: a) synthesis of hydrated Ca-silicates; b) structural analysis of cement phases during heating and dehydration/rehydration; c) mechanistic and thermodynamic descriptions of the hydration/dehydration behavior of hydrated $\mathrm{Ca}$-silicates as a function of temperature, pressure and relative humidity; d) study of naturally occurring hydrated $\mathrm{Ca}$-silicates; and e) measurements of thermodynamic data for hydrated Ca-silicates.
\end{abstract}

\section{INTRODUCTION}

Large quantities of cementitious materials may be used in the construction of a potential nuclear waste repository. The U. S. Dept. of Energy Site Characterization Plan design calls for $560,000 \mathrm{~m}^{3}$ of shotcrete in the emplacement drifts alone. ${ }^{1}$ Temperatures in the emplacement drifts may reach over $200^{\circ} \mathrm{C}$ owing to decay heat from radioactive waste for various "extendeddry" repository scenarios. ${ }^{2}$ Despite its potential significance, the mineralogic response of cement to elevated temperature is not well known. The chemistry of fluid introduced to the repository from cementitious materials can also have a significant impact on repository performance. The masses of water associated with the use of cementitious materials such as shotcrete, which includes both structural and pore water, can be sizable. Pore water may be driven out by heating, and structural water may be released through phase dehydration.

Released water may react with surrounding fluids, rocks and man-made materials to produce new minerals. Because fluids from dehydrated cements and fluids that react with altered cements could control the chernistry of waters in proximity to the waste packages, they could affect radionuclide solubilities and waste canister corrosion. They may also affect how surrounding host rocks are modified. by the elevated temperatures and fluid flow caused by waste emplacement. As another consequence, a cement that has been heated and then cooled may differ substantially in its physical and chernical properties from its initial state.

Evaluations of the long-term (10,000 years) response of cement to changes in the physical and chemical environment can be conducted analogously to evaluations of how the host rocks will respond. Both cements and rocks are composed of phases that dissolve and precipitate, and whose presence affects the chemistry of associated fluid phases, and vice versa. For such predictions, we require thermodynamic data for high temperature cement phases. These data are either unavailable or inadequate at present. Geochemical simulations of cement-water interactions made using the available estimated data were limited mainly to $25^{\circ} \mathrm{C}\left(\right.$ e.g., ${ }^{3}$ ), and were carried out by suppressing precipitation of those phases not expected to form owing to kinetic constraints. When elevated temperatures are considered over long periods of time, such simplifying assumptions

\section{MASTER}

DISTRIBUTION OF THIS DOCUMENT IS UNLIMITED 
cannot be made and relative mineral stabilities must be accurately assessed because kinetic inhibitions become less restrictive. Measurement and estimation of thermodynamic properties are complicated by the fact that many of the cement minerals are hydrous. The quantity and thermodynamic activity of water in a nuclear waste repository sited in the unsaturated zone can vary significantly, and thus will impact the stability of hydrous phases.

The purpose of this project is to determine the structural characteristics of the minerals that form in cement at elevated temperature, and to determine the thermodynamic properties of these phases. Knowledge of the structural properties of minerals allows us to model their physical and chemical properties more accurately. Information from this project will ultimately be incorporated into evaluations of the mineralogic response of cementitious materials to elevated temperatures and fluid movement, and into determinations of how cements modify or "condition" fluid chemistry. Work carried out to define the scope of the project will be described in this paper, and results will be presented that demonstrate the key role that structural analysis plays in the project.

\section{CEMENT MINERALS AND THEIR THERMODYNAMIC PROPERTIES}

Hydrated cements prior to aging consist largely of $\mathrm{Ca}(\mathrm{OH})_{2}$ and what is known as C-S-H gel, 4,5 which is poorly crystalline, hydrous, and composed of $\mathrm{Ca}(\mathrm{C}), \mathrm{Si}(\mathrm{S})$ and $\mathrm{H}_{2} \mathrm{O}(\mathrm{H})$. A form of reactive $\mathrm{SiO}_{2}$ is often present as well. Upon aging and/or heating, these phases convert to a variety of hydrated $\mathrm{Ca}$-silicates such as tobermorite, afwillite, hillebrandite, foshagite, xonotlite, reyerite, gyrolite and truscottite (Table 1, Figure 1).

TABLE 1. Mineral compositions

\begin{tabular}{|l|l|}
\hline $\begin{array}{l}\text { 9.7, 11.3, and } 14 \AA \\
\text { tobermorite }\end{array}$ & $\mathrm{Ca}_{5} \mathrm{Si}_{6} \mathrm{O}_{16}(\mathrm{OH})_{2} \cdot \mathrm{nH}_{2} \mathrm{O}$ \\
\hline afwillite & $\mathrm{Ca}_{3} \mathrm{Si}_{2} \mathrm{O}_{4}(\mathrm{OH})_{6}$ \\
\hline hillebrandite & $\mathrm{Ca}_{2} \mathrm{SiO}_{3}(\mathrm{OH})_{2}$ \\
\hline foshagite & $\mathrm{Ca}_{4} \mathrm{Si}_{3} \mathrm{O}_{9}(\mathrm{OH})_{2}$ \\
\hline xonotlite & $\mathrm{Ca}_{6} \mathrm{Si}_{6} \mathrm{O}_{17}(\mathrm{OH})_{2}$ \\
\hline reyerite & $\begin{array}{l}\left(\mathrm{Na}_{2} \mathrm{~K}_{2} \mathrm{Ca}_{14}-\right. \\
\left(\mathrm{Si}_{1} \mathrm{Al}_{24} \mathrm{O}_{58}(\mathrm{OH})_{8} \cdot 6 \mathrm{H}_{2} \mathrm{O}\right.\end{array}$ \\
\hline gyrolite & $\mathrm{Ca}_{4} \mathrm{Si}_{6} \mathrm{O}_{15}(\mathrm{OH})_{2} \cdot 4 \mathrm{H}_{2} \mathrm{O}$ \\
\hline truscottite & $\mathrm{Ca}_{14} \mathrm{Si}_{24} \mathrm{O}_{58}(\mathrm{OH})_{8} \cdot 2 \mathrm{H}_{2} \mathrm{O}$ \\
\hline okenite & $\mathrm{Ca}_{10} \mathrm{Si}_{18} \mathrm{O}_{46} \cdot 18 \mathrm{H}_{2} \mathrm{O}$ \\
\hline nekoite & $\mathrm{Ca}_{3} \mathrm{Si}_{6} \mathrm{O}_{12}(\mathrm{OH})_{6} \cdot 5 \mathrm{H}_{2} \mathrm{O}$ \\
\hline
\end{tabular}

${ }^{a}$ referred to as $9 \AA, 11 \AA$ and $14 \AA$ tobermorite in this paper

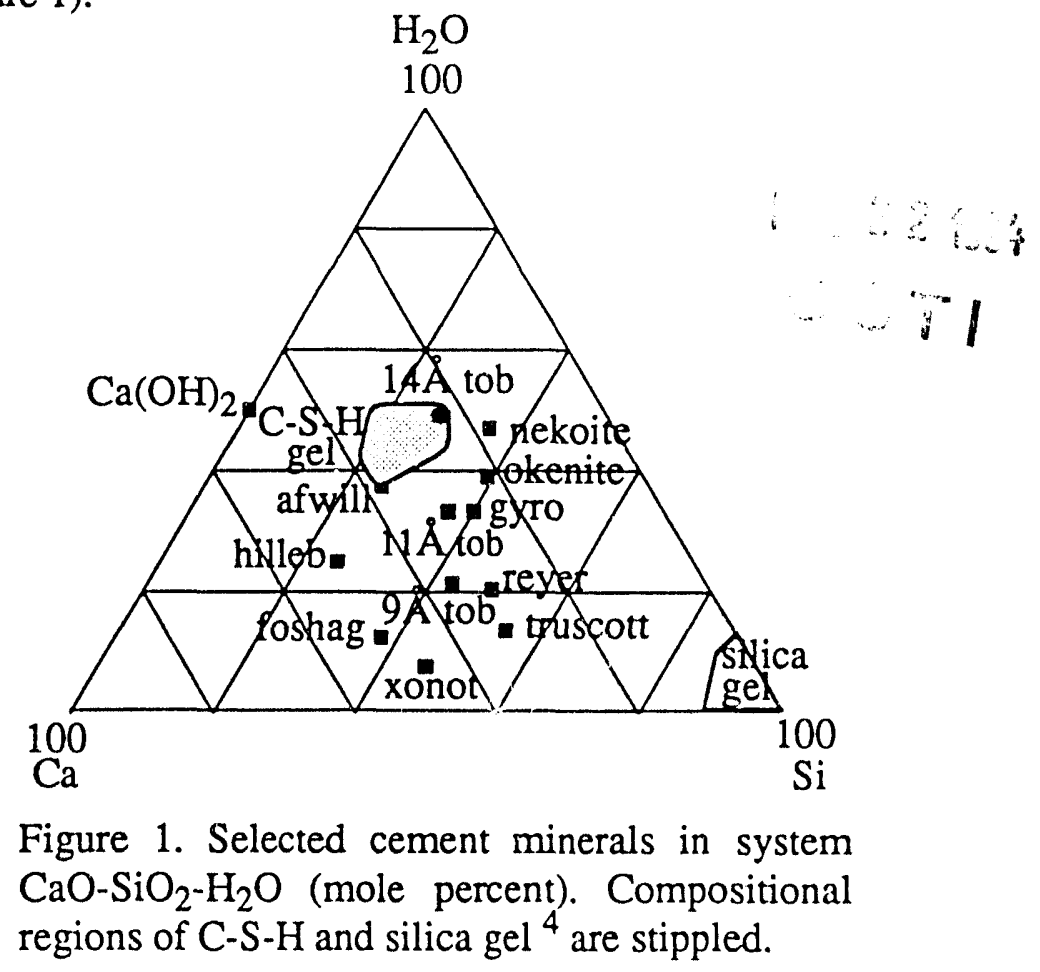

The above minerals vary in their atomic structures, $\mathrm{Ca}-\mathrm{Si}$ ratio, and $\mathrm{H}_{2} \mathrm{O}$ and $\mathrm{OH}$ content. (The term "hydrated" as used in this paper refers to the presence of $\mathrm{OH}$ and/or $\mathrm{H}_{2} \mathrm{O}$ in a mineral.) We have initially focused on this suite of minerals as representative of the chemical system $\mathrm{CaO}$ $\mathrm{SiO}_{2}-\mathrm{H}_{2} \mathrm{O}$, which is a primary component of cement-water systems. Future studies will expand the compositional system to include $\mathrm{SO}_{4}, \mathrm{Al}, \mathrm{Fe}$ and other components found in typical cements. 
Extensive literature reviews have revealed that thermodynamic data (e.g., ${ }^{6,7}$ ) are sparse for these minerals, and the available data are contradictory. The contradictions arise because minerals were not characterized adequately prior to measurements, and their hydration states were either guessed, estimated, or were not controlled during the measurements. As a result, significant differences exist among experimentally determined thermodynamic values for minerals with the same reported chemical formula.

Thermodynamic data for some of the phases of interest have been estimated ${ }^{8}$ based on structural interpretations and average bond energies obtained from minerals whose thermodynamic properties are known. However, we have several reasons to re-evaluate these estimated values, even though the data have been used in thermodynamic calculations of cement stability at $25^{\circ} \mathrm{C}$ (e.g., ${ }^{3}$ ). The enthalpies of minerals used in the estimations differ from accepted values for those minerals today. In addition, the Ca-silicate hydrates are unique structures. No compositional or structural analogues to the hydrated $\mathrm{Ca}$-silicate are known to exist. ${ }^{4}$ As a consequence, one is forced to question the appropriateness of estimation techniques based on the assumed similarity of bond energies, especially at elevated temperature.

The estimation techniques that have been applied to the hydrated $\mathrm{Ca}$-silicates do not provide for the energetics of hydration/dehydration. Johnson et al. ${ }^{9}$ have shown that for hydrated phases such as zeolites, the energetic contribution of zeolitic $\mathrm{H}_{2} \mathrm{O}$ is significant, but is unique to each mineral, is not constant and does not seem to follow a pattern.

Considered as an isolated group, the estimated data seem to agree with the relative stability of these phases. However, it has not been demonstrated that the data are consistent with those for other minerals included in the thermodynamic data bases associated with geochemical modeling codes. Assuring that our data set is internally consistent is critical to the successful evaluation of interactions among cement minerals and host rock minerals.

\section{EXPERIMENTAL PROGRAM}

In view of the above needs, a multidisciplinary experimental and modeling program has been designed to elucidate the structuri: and thermodynamic response of cement minerals to elevated iemperature. The program includes: a) synthesis of hydrated Ca-silicates; b) structural analysis of cement phases during heating and dehydration/rehydration; c) mechanistic and thermodynamic descriptions of the hydration/dehydration behavior of hydrated $\mathrm{Ca}$-silicates as a function of temperature, pressure and relative humidity; d) study of natura!ly occurring hydrated Ca-silicates; and e) measurements of thermodynamic data for hydrated Ca-silicates. The following sections summarize recent results in these areas except for a) and d), which are described elsewhere. ${ }^{10}$

\section{Structural analysis}

Structural changes in natural and synthetic phases that occur during heating and dehydration/ rehydration are being assessed by computer-based molecular modeling, X-ray diffraction (XRD) and nuclear magnetic resonance (NMR) spectroscopy.

Molecular modeling. We are using published atomic parameters and molecular simulation software $^{11}$ to construct a visual library of three-dimensional Ca-silicate hydrate crystal structures and their simulated $\mathrm{x}$-ray diffraction patterns. The crystal structure library will be used to verify structural modifications that occur during the course of experiments. Structural modifications are apparent from changes in the relative intensities and positions of the peaks in $\mathrm{x}$-ray diffraction 
patterns, which can be compared to simulated patterns (see $X$-ray diffraction).

The geometric relationship between an ion and its nearest neighbors reflects the cation-oxygen bonding relationship, which is fundamental to the thermodynamic characteristics of the material. This geometric relationship, or ion coordination, is the basis for thermodynamic estimation techniques that have been applied to the Ca-silicate hydrates. ${ }^{8}$ The applicability of these techniques requires verification because the calcium ion coordination of many of the Ca-silicate hydrate: is thought to differ from that in other common silicate structures.

Previous thermochemical models for the $\mathrm{Ca}$-silicate hydrates ${ }^{8}$ use a $\mathrm{Ca}-\mathrm{O}$ binding energy determined from wollastonite $\left(\beta-\mathrm{CaSiO}_{3}\right)$. The $\mathrm{Ca}-\mathrm{O}$ bonding polyhedra in wollastonite (Figure 2a) contain six or seven oxygens at an average distance of 2.37 to $2.41 \AA$ with a standard deviation of 0.07 to $0.12 \AA$. In contrast, $\mathrm{Ca}$-silicate hydrates display a wide variety of $\mathrm{Ca}-\mathrm{O}$ bonding polyhedra, some of which contain water molecules. For example, tobermorite (Figure 2b-d) contains three types of $\mathrm{Ca}$-sites that vary greatly in both mean $\mathrm{Ca}-\mathrm{O}$ distance ( 2.42 to $2.94 \AA$ ) and regularity (standard deviation 0.05 to $0.30 \AA$ ). The appropriateness of a thermochemical estimation technique based on wollastonite must therefore be questioned.

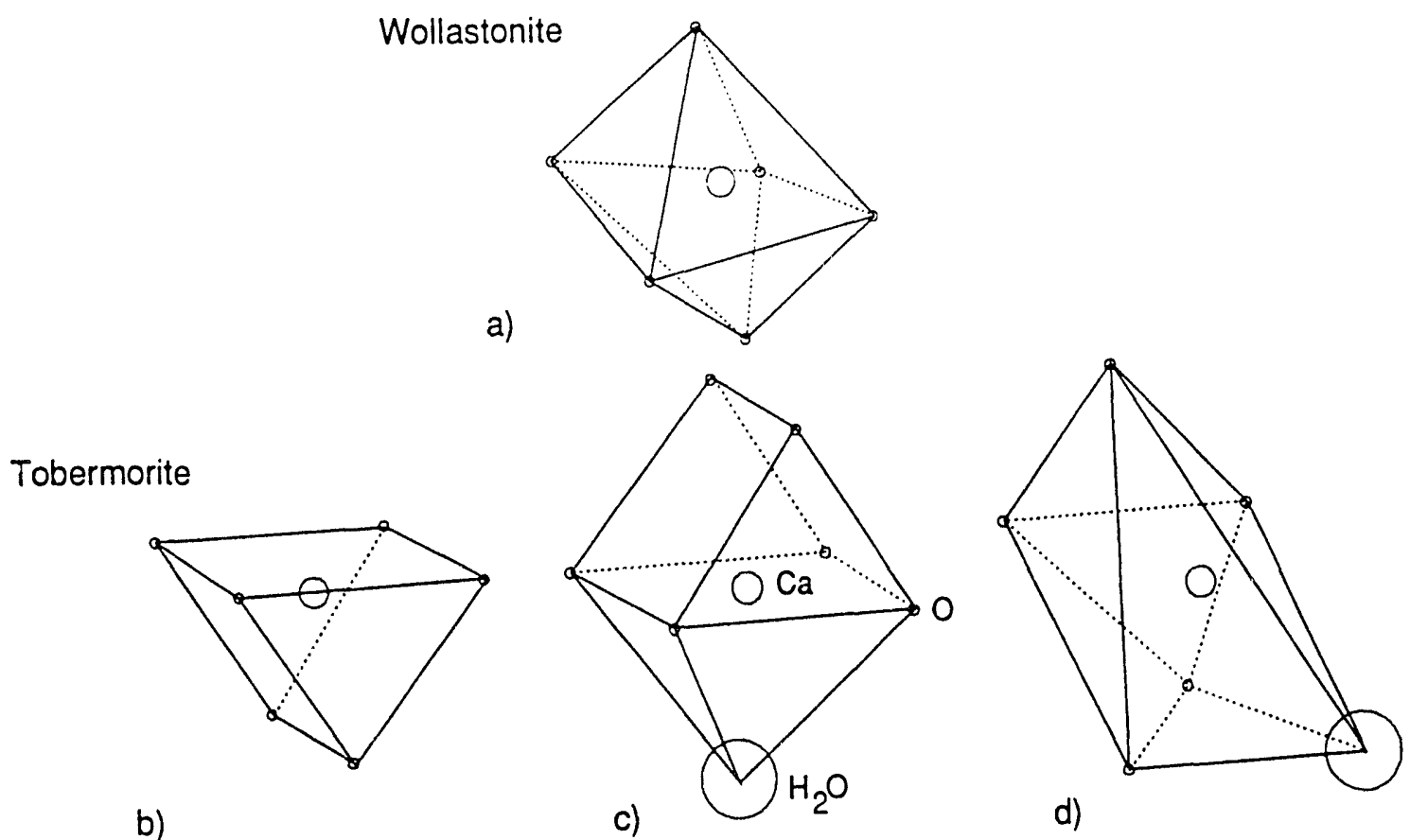

Figure 2. Ca-O bonding polyhedra for wollastonite (a) and tobermorite (b, c, d; after ${ }^{12}$ ). Small circles are oxygen atoms and large circles are $\mathrm{H}_{2} \mathrm{O}$ molecules.

$X$-ray diffraction. XRD is being used to determine whether structural changes accompany dehydration/rehydration. Knowledge of the hydration state is required to quantify the amount and timing of water released to the repository from these materials, and to evaluate of the energetics of the materials throughout the repository lifetime. Documentation of the dehydration characteristics of the Ca-silicate hydrates will constitute a major part of the present investigation. 
Changes in hydration state (structural $\mathrm{OH}$ and $\mathrm{H}_{2} \mathrm{O}$ ) can modify the atomic structure of a material to various degrees, depending on a number of factors. For example, it is known that the removal of water from tobermorite appears to decrease the spacings of one set of parallel layers to a far greater extent than the others. Thus, the three identified tobermorite phases are named $9 \AA$, $11 \AA$ and $14 \AA$ after those diagnostic layer spacings.

Preliminary studies suggest that material originally synthesized as a mixture of $14 \AA$ and $11 \AA$ tobermorite dehydrates to $11 \AA$ tobermorite upon heating to $110^{\circ} \mathrm{C}$. Comparison of the XRD patterns of the post-heating sample and the simulated $11 \AA$ tobermorite (Figure 3 ) to the air-dried 42 day sample (not shown) illustrates the structural change upon dehydration. Our preliminary results suggest that in agreement with previous studies, $11 \AA$ rather than $14 \AA$ tobermorite, will be the dominant phase at elevated temperature in the repository environment.

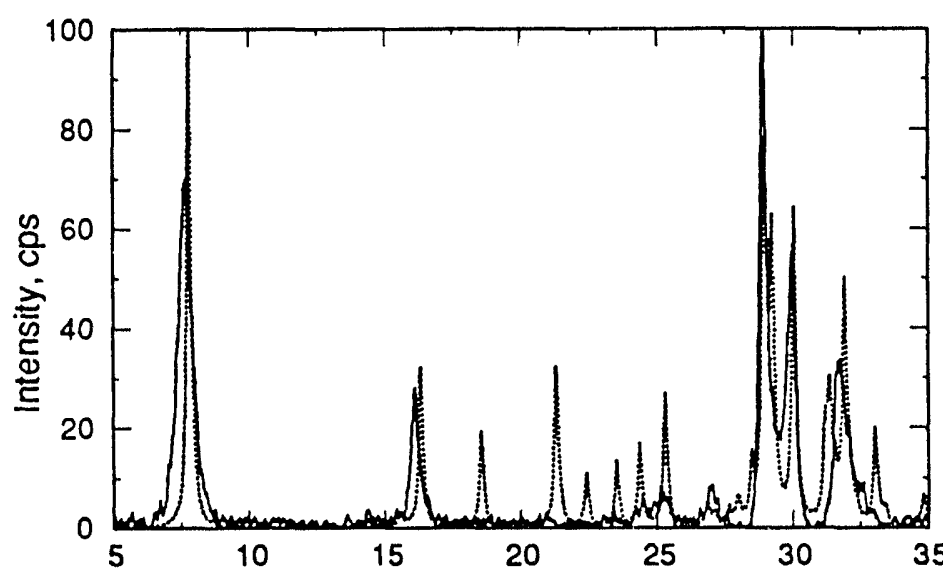

Degrees 2- $\theta$

Figure 3. X-ray diffraction pattern of the 42 day synthesized sample dried at $110^{\circ}$ (solid line) superimposed upon a simulated pattern of $11 \AA$ tobermorite (dotted line).

Nuclear magnetic resonance spectroscopy. NMR spectroscopic data are being collected for hydrated Ca-silicates under ambient conditions to deduce the structures of materials on a molecular level. Such data form the basis from which structural changes during dehydration/rehydration can be assessed. ${ }^{29} \mathrm{Si}$ and ${ }^{1} \mathrm{H}$ NMR data have been collected for gyrolite, okenite, xonotlite, hillebrandite and a synthetic tobermorite, and ${ }^{1} \mathrm{H}$ data have been collected for portlandite and ettringite.

For ${ }^{29} \mathrm{Si}$, two basic magic-angle-spinning (MAS) experiments were performed- single-pulse (SP) and ${ }^{29} \mathrm{Si}\left({ }^{1} \mathrm{H}\right\}$ cross-polarization (CPMAS). All ${ }^{1} \mathrm{H}$ MAS spectra are from SP experiments. ${ }^{29} \mathrm{Si}$ peak positions for the hydrated $\mathrm{Ca}$-silicates depend mostly on the degree of polymerization (i.e., number of bridging oxygens), and are designated $\mathrm{Q}^{\mathrm{n}}$, where $\mathrm{n}$ is the number of bridging oxygens.

The crystal structure of gyrolite is shown in Figure 4. The ${ }^{29} \mathrm{Si}$ SP and CPMAS NMR spectra of gyrolite (Figure 5, top and bottom, respectively) contain strong $\mathrm{Q}^{3}$ peaks at $-91.8,-93.5$, and $-98.8 \mathrm{ppm}$, consistent with the proposed sheet silicate structure. ${ }^{13}$ For a synthetic gyrolite, Bell et al. ${ }^{14}$ observed additional, relatively intense peaks at -80 and $-86 \mathrm{ppm}$ due to $\mathrm{Q}^{1}$ and $\mathrm{Q}^{2}$ environments, respectively. Our spectra show only a small $\mathrm{Q}^{2}$ peak at $-84.6 \mathrm{ppm}(0.4 \pm 0.1$ percent $)$ and another, broader peak at about $-88.5 \mathrm{ppm}$ that is probably also due to $\mathrm{Q}^{2}$. The much lower concen- 


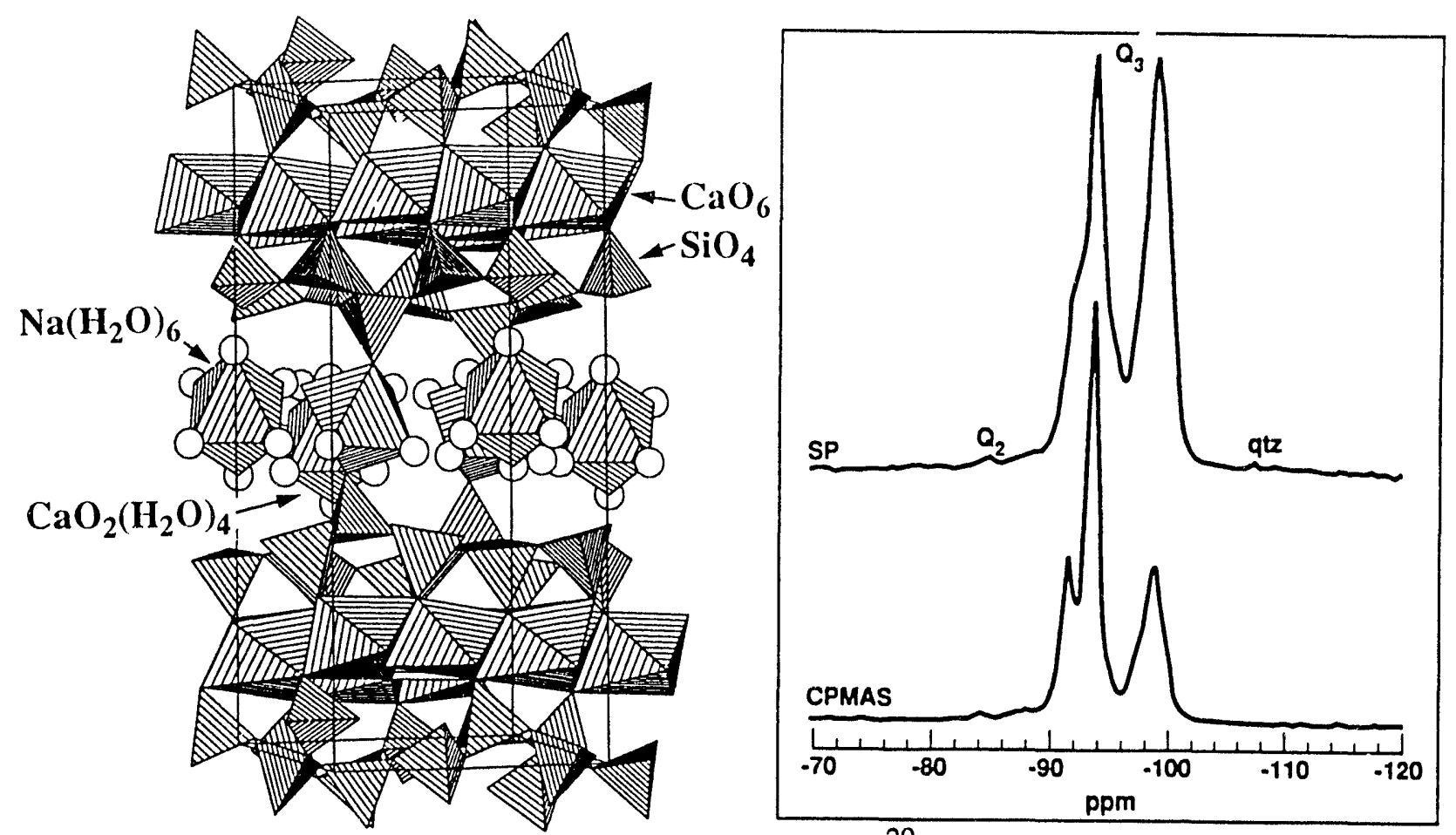

Figure 4. Atomic structure of gyrolite $\left(\right.$ after ${ }^{13}$ ). Sample contains small amount of $\mathrm{Na}$.

Figure $5 .{ }^{29} \mathrm{Si}$ SP and CPMAS NMR spectra of gyrolite are consistent with proposed sheet silicate structure (see Figure 4).

tration of $Q^{2}$ Si sites and the narrower peaks for the natural material indicate that it is more ordered than the synthetic sample examined by Bell et al. ${ }^{14}$ These ordering differences could translate into significant energetic differences. This finding underscores the need for careful sample characterization before thermodynamic or other analyses are conducted.

${ }^{1}$ H MAS NMR spectra for xonotlite and gyrolite are shown in Figure 6. Xonotlite gives a single hydroxyl peak at $+2.4 \mathrm{ppm}$, in agreement with the accepted structural formula. Gyrolite has a broad peak at $+5.1 \mathrm{ppm}$ for structural water, a narrow peak at +1.5 (width $0.6 \mathrm{ppm}$ ) due to isolated hydroxyls, and a broader hydroxyl peak at $+2.2 \mathrm{ppm}$ (width $1.6 \mathrm{ppm}$ ). The main hydroxyl peaks are probably from the octahedral sheet and the structural water from the interlayer. These ${ }^{1} \mathrm{H}$ results indicate that it will be possible to determine the changes in the hydrogen speciation upon dehydration.

\section{Dehydration/rehydration behavior}

The thermodynamic behavior of the hydrous $\mathrm{Ca}$-silicates as a function of temperature, pressure and relative humidity will be deduced from experimentally determined water sorption isotherms. Hydrated Ca-silicates will also be equilibrated at varying relative humidities within an environmental chamber attached to the XRD. Water is associated with the external (intercrystalline water) and internal (intracrystalline water) surfaces of these hydrates. Loss of external, interparticle water will be reflected by weight loss without associated structural changes. Loss of such water can, however, affect the release of water into the environment surrounding cements. 


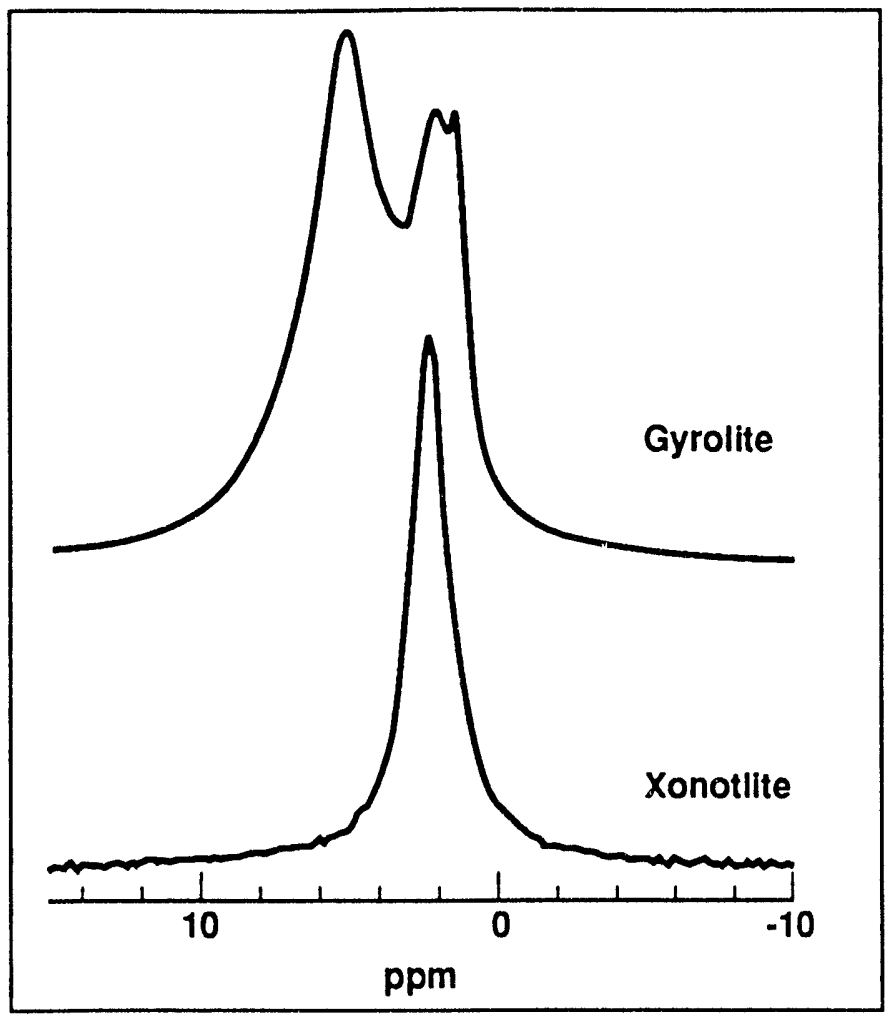

Figure 6. ${ }^{1} \mathrm{H}$ MAS NMR spectra of xonotlite and gyrolite illustrating the distinction between structural water and hydroxyls.

\section{Thermodynamic models}

Standard experimental techniques designed to obtain thermodynamic data for anhydrous minerals will encounter problems when applied to hydrated minerals owing to the changes in hydration state that can occur during the course ot a measurement. Such behavior confounds interpretation of the results. We must therefore develop an understanding of the hydration/dehydration behavior of hydrated phases as a function of temperature, pressure and relative humidity.

As part of an international agreement between the U.S. Dept. of Energy and the Atomic Energy of Canada Limited, differential scanning calorimetry (DSC) will be used to measure high temperature heat capacities of cement minerals. Heat capacity data are required to predict mineral stability at elevated temperature, and our present heat capacity values for common cement minerals are estimated. Current work in this area is directed at controlling the hydration state of phases during the DSC scan, and to determining properties of phases with limited water loss. 


\section{CONCLUSIONS}

Data from the above studies should provide the basis for describing the high-temperature behavior of cement minerals, their impact on water chemistry and their interactions with the surrounding host rock and waste canisters. Our preliminary studies demonstrate the limitations of available thermodynamic data, and emphasize the importance of determining cement mineral behavior as a function of temperature, pressure, and relative humidity.

In agreement with previous studies, $11 \AA$ tobermorite should become the dominant tobermorite phase as temperatures increase. NMR spectroscopy suggests that significant energetic differences could exist between synthetic and natural samples selected for calorimetric studies. NMR has also proven capable of determining changes in hydrogen speciation during dehydration of cement minerals.

\section{ACKNOWLEDGEMENTS}

This work was performed under the auspices of the U.S. Dept. of Energy by Lawrence Livermore National Laboratory under Contract W-7405-ENG-48. Financial support for this project was obtained from the Fundamental Materials Investigations activity of Subsidiary Agreement No. 2 between Atomic Energy of Canada Limited and the U. S. Dept. of Energy as part of the Civilian Radioactive Waste Management Program.

\section{REFERENCES}

1. U.S. Dept. of Energy, Site Characterization Plan, Yucca Mountain Site, Nevada Research and Development Area, Nevada (Office of Civilian Radioactive Waste Management, Washington, D.C., 1988).

2. T.A. Buscheck and J.J. Nitao, Proc. of Fourth Intl. High Level Radioactive Waste Mgmt. Conf., Las Vegas, NV, 1993, p. 847-867.

3. S.R. Alcorn, T.L. Christian-Frear, and M.G. Wallace, Nuclear Waste Commission of Finnish Power Companies Report YJT-91-09 (1991).

4. H.F.W. Taylor, The Chemistry of Cements (Academic Press, New York, 1964).

5. F.P. Glasser, M.J. Angus, C.E. McCulloch, D. Macphee, and A.A. Rahman in Scientific Basis for Nuclear Waste Management, ed. by C.M. Jantzen, J.A. Stone and R.C. Ewing (Mater. Res. Soc. Proc. 44, Pittsburgh, PÁ, 1985) pp. 849-858.

6. E.S. Newman, J. Res. of Natl. Bur. Standards Research Paper 2690, 57, 27 (1956).

7. J.E. Taylor, Proc. 9th Conf. Silicate Ind., Budapest (1968), pp. 179-184.

8. V.I. Babushkin, G.M. Matveyev, and O.P. Mchedlov-Petrossyan, Thermodynamics of Silicates (Springer-Verlag, New York, 1985).

9. G.K. Johnson, I.R. Tasker, R. Jurgens, and P.A.G. O'Hare, J. Chem. Thermo. 23, 475 (1991).

10. C.J. Bruton, A. Meike, B.E. Viani, S. Martin, and B.L. Phillips, Proc. of FOCUS93, Las Vegas, NV, Sept. 27-29, 1993, in press.

11. CERIUS molecular modeling software, Molecular Simulations Inc., Burlington, MA.

12. S.A. Hamid, Zeitschrift fur Krist. 154, 189 (1981).

13. S. Merlino, Min. Mag. 52, 377 (1988).

14. G.M.M. Bell, J. Bensted, F.P. Glasser, E.E. Lachowski, D.R. Roberts, and M.J. Taylor, Adv. Cement Res. 3, 23 (1990). 

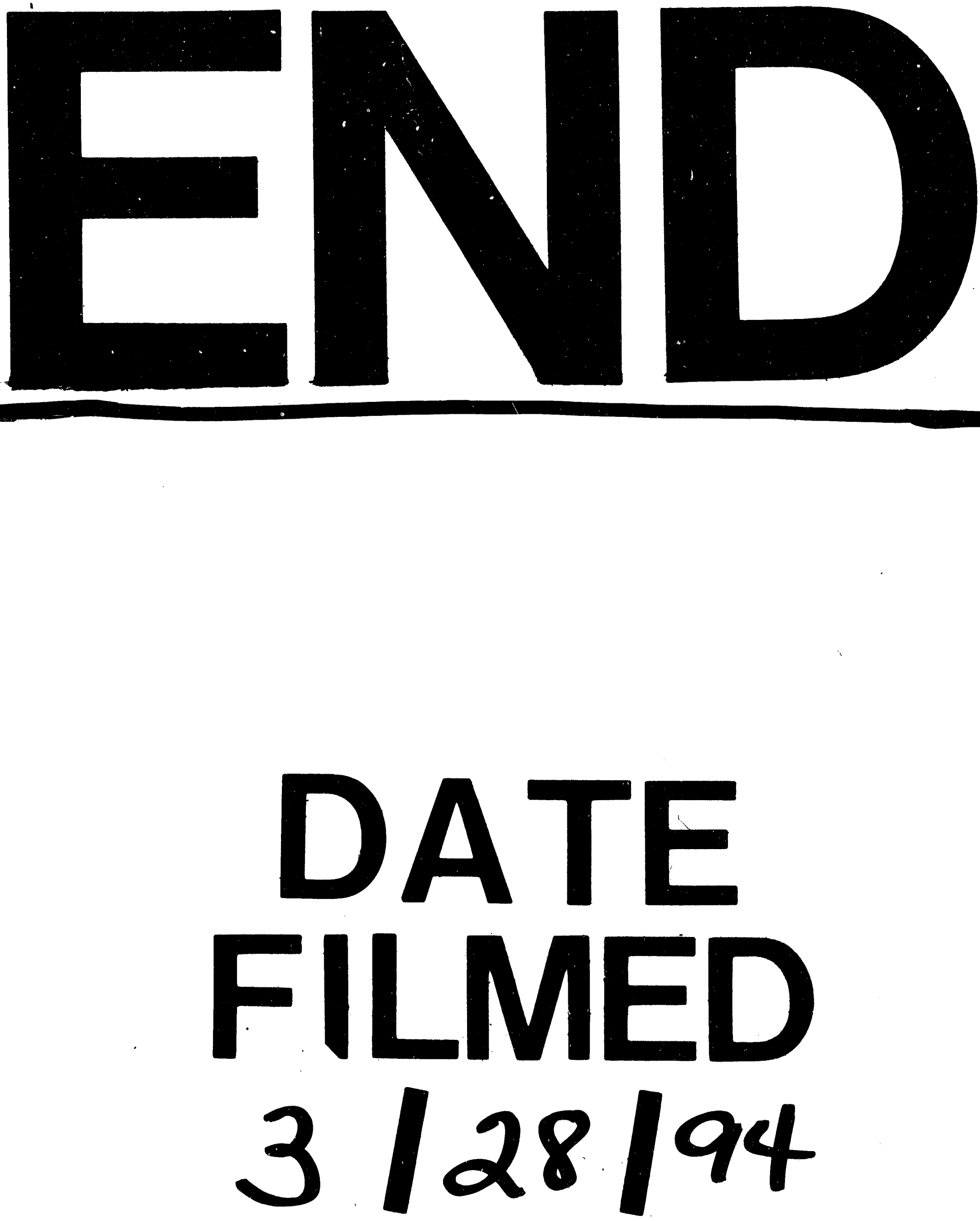


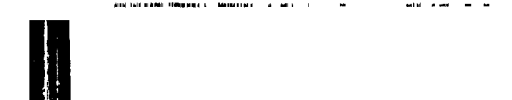

